\title{
Modelo de análise de investimentos para fabricação de produtos ecologicamente corretos
}

\author{
Investment analysis model for green manufacturing
}

\author{
Geysler Rogis Flor Bertolini' \\ Cláudio Antonio Rojo ${ }^{1}$ \\ Álvaro Guilhermo Rojas Lezana ${ }^{2}$
}

\begin{abstract}
Resumo: As pressões da sociedade, consumidores, governo e outras organizações no cuidado com o meio ambiente levam algumas empresas a adotar medidas sobre seus impactos ambientais. A decisão de cuidar das questões ambientais precede a escolha da forma de agir, podendo ser desde a seleção de insumos adequados até a certificação da ISO 14001. Para cada possibilidade de cuidados com o meio ambiente, a empresa necessita de recursos financeiros para viabilizar o projeto. O objetivo deste artigo é de apresentar um modelo de análise de viabilidade na fabricação de produtos com alguma preocupação ambiental. Considerando que nos modelos já existentes não é realizada uma mensuração do valor para os consumidores para dar suporte às decisões de investimentos sobre a variável ambiental nas organizações, este estudo busca preencher esta lacuna. O modelo proposto é composto por seis etapas. Espera-se que este modelo genérico possa servir de apoio para as organizações definirem o volume de investimentos necessários para uma equilibrada gestão ambiental.
\end{abstract}

Palavras-chave: Produtos ecológicos. Investimentos. Valor.

\begin{abstract}
Demands of society, consumers, government, and other organizations for care of the environment, have led some companies to adopt environmental impact measures. The decision about caring for the environment precedes the choice of measures to be taken, which include from the selection of appropriate inputs to the ISO 14001 certification. Funds are necessary for every potential environmental care project. The aim of this paper is to present a feasibility analysis model for environmentally conscious manufacturing. Considering the fact that there is no measurement of value for consumers in the existing models to support investment decisions on environment variables in organizations, this study seeks to bridge this gap. The proposed model consists of six steps. It is expected that this generic model can help organizations define the volume of investments required for a balanced environmental management.
\end{abstract}

Keywords: Green products. Investments. Value.

\section{Introdução}

Entre as causas que levam as organizações a adotar ações ligadas às questões ambientais, estão as relacionadas ao mercado (melhoria da imagem da organização, diferenciação dos concorrentes, concorrência, mudança nas atitudes de compra de clientes). Tais causas influem diretamente na rentabilidade e sobrevivência das empresas, pois a questão ambiental pode ser provedora de vantagem competitiva para as organizações.

Donaire (2001) afirma que atitudes e medidas para não poluir ou poluir menos, se tornam condição fundamental para bons negócios e para a sobrevivência da empresa no mercado, pois, para as empresas que desprezam a oferta de produtos ecologicamente corretos, as portas do mercado e do lucro se reduzem constantemente.
São diversas as maneiras de agir das organizações, algumas adotam uma política de seleção no momento da compra de matérias-primas e produtos ecologicamente corretos, fazendo com que seu produto seja originado de fontes ecológicas. Outras organizações buscam o máximo de cuidado no momento de produção, gerenciando todas as etapas do ciclo produtivo do bem para que minimizem o impacto ao meio ambiente. Há também aquelas empresas que se preocupam com a destinação de seu produto após seu uso pelo cliente, procurando orientar o melhor modo de descarte ou reaproveitamento do produto utilizado.

Várias empresas possuem uma gestão ambiental estabelecendo políticas, programas e procedimentos para levar a organização a realizar suas atividades

\footnotetext{
${ }^{1}$ Universidade Estadual do Oeste do Paraná - UNIOESTE, CEP 85819-110, Cascavel, PR, Brasil, e-mail: geysler@unioeste.br; rojo@unioeste.br

${ }^{2}$ Universidade Federal de Santa Catarina - UFSC, Trindade, CEP 88040-900, Florianópolis, SC, Brasil, e-mail: lezana@ deps.ufsc.br Recebido em 21/5/2010 — Aceito em 6/6/2012
}

Suporte financeiro: Nenhum. 
gerando o menor impacto ao meio ambiente (ANDRADE; TACHIZAWA; CARVALHO, 2002). Algumas já utilizam a ISO 14.001 para gerenciar a questão ecológica, estabelecendo diretrizes para o uso de cada atividade relacionada ao meio ambiente.

Independentemente de como a organização vai trabalhar, é possível utilizar esta nova postura para se promover no mercado, mostrando aos consumidores que valorizam a oferta de produtos ecologicamente corretos que a empresa se preocupa com o meio ambiente. Porém, para cada possibilidade de cuidados com o meio ambiente, a empresa necessita de recursos financeiros para viabilizar o projeto. O investimento é necessário, pois, para cada mudança na organização, existem custos para a adequação das atividades.

Sabe-se que a análise de investimentos é imprescindível nas organizações que possuem projetos alternativos de melhoria, e em projetos ambientais isso não é diferente. É necessário analisar sua viabilidade buscando o retorno adequado para a empresa, pois certos volumes de investimentos podem não proporcionar o resultado esperado.

Em face do exposto, pôde-se formular a seguinte pergunta de pesquisa: como saber se investimentos na fabricação de produtos com características ecológicas serão viáveis? Assim, este trabalho apresenta um modelo de análise de investimentos para fabricação de produtos com alguma característica ecológica.

Nos últimos anos, estudos como os de Silva (2001), Passos (2003), Alberton (2003), Borba (2006) e Cesar e Silva Junior (2008) relacionam a performance competitiva e econômica com a variável ambiental, em que são utilizadas informações e aspectos passados de setores específicos, ou seja, quais os resultados adquiridos com as decisões já tomadas em relação ao meio ambiente. Recentemente, Orellano e Quiota (2011) investigaram a relação entre os investimentos socioambientais e o desempenho financeiro das empresas brasileiras de 2001 a 2007. Os resultados revelam uma correlação positiva entre investimento socioambiental e desempenho financeiro, sobretudo o investimento social interno. O caráter de ineditismo do presente estudo está na falta de estudos que realizem previsões de retorno sobre investimentos nas questões ambientais das organizações.

Outros modelos, relacionando a variável ambiental e competitividade, podem ser citados. Epelbaum (2004) propõe uma ferramenta para avaliação estratégica ambiental, na qual analisa se os fatores ligados a produtos, processos e setores modificam ou influenciam a gestão ambiental da organização.

O modelo de Avaliação da Estratégia Ambiental (ECP-Ambiental), de Abreu (2001), é resultado da inserção das variáveis ambientais desenvolvidas no modelo ECP (Estrutura-Conduta-Performance). Os elementos que compõem o modelo são: choques externos, indicadores da estrutura do mercado, indicadores da conduta ambiental e indicadores da performance ambiental. O modelo permite inferir que a performance ambiental de uma empresa é o reflexo de seus padrões de conduta ambiental, que, por sua vez, dependem da estrutura de mercado em que está inserida.

O Modelo de Valoração Ambiental para Análise de Propostas de Investimento, de Barbosa Filho (2005), está fundamentado na Avaliação Custo-Benefício (CBA) e no Método de Avaliação Contingente (CVM) pela incorporação dos custos e benefícios ambientais como parte essencial do modelo, visando com isso fornecer uma visão mais completa dos projetos avaliados e, ainda, ajudar os tomadores de decisão na utilização sustentável dos recursos naturais.

Observa-se na análise de tais modelos uma lacuna a ser preenchida, pois não é realizada uma mensuração do valor para os consumidores para dar suporte às decisões de investimentos sobre a variável ambiental nas organizações. Para Bockermann et al. (2005), existe a necessidade de modelos estratégicos para a tomada de decisão, relacionando a performance ambiental, as necessidades das partes interessadas e os impactos econômicos da escolha estratégica.

\section{Sistemas de Gestão Ambiental: fundamentação teórica}

Para Fa et al. (2003), Sistemas de Gestão Ambiental (SGA) são ferramentas que companhias podem usar realizando um alto desempenho de proteção ambiental dentro do contexto de desenvolvimento sustentável. O SGA não deve ser entendido como o gerenciamento do meio ambiente, mas, segundo Walker et al. (2007), seu conceito deve ser visto como o redirecionamento das atividades humanas que tenham considerável impacto sobre o meio ambiente, com o objetivo de minimizá-los.

Para Watson e Emery (2004), os SGAs são projetados para facilitar o cumprimento das regulamentações ambientais e para satisfazer as necessidades de todas as partes organizacionais interessadas. Os incentivos para introduzir tais sistemas variam em todo o mundo e são influenciados pelos regulamentos nacionais e pressões das partes interessadas.

Conforme Durán e Puglia (2007), um SGA pode contribuir para um bom desempenho ambiental, melhoria nos resultados financeiros e efeitos operacionais positivos, desde que o sistema possa melhorar os processos e a imagem que os stakeholders possuem da organização. Conforme Freimann e Walther (2001), um SGA normalmente consiste em políticas, procedimentos, protocolos e auditoria para as operações que geram resíduos ou emissões. A visão sistêmica na gestão ambiental é necessária, conforme Gavronski, Ferrer e Paiva (2008), os 
impactos ambientais não devem ser analisados isoladamente em uma etapa do processo produtivo.

Conforme Rohrich e Cunha (2004), não é padrão o trabalho ou a preocupação das organizações quanto à questão ambiental, assim, várias pesquisas sobre a gestão ambiental nas empresas classificam de três a cinco níveis onde é possível identificar a postura ambiental da empresa. No Brasil, esses estudos constataram a diversidade de práticas na gestão ambiental das empresas pesquisadas. As variações desses níveis são relacionadas pelo tipo de produto, processo e tecnologia utilizada, pelo seu porte, setor e área de abrangência. O Quadro 1 apresenta os estágios dos sistemas de gestão ambiental que podem ser encontrados nas organizações.

Verifica-se, com a apresentação destes níveis de gestão ambiental, que, conforme a postura da empresa em relação aos cuidados com a questão ambiental, ela será classificada não somente pelos pesquisadores, mas pela sociedade, pelos clientes, concorrentes, fornecedores e mercado. Assim, há uma relação direta sobre a percepção e atitude dos stakeholders da postura ambiental das organizações. (BRANDALISE et al., 2009; ZUTSHI; SOHAL, 2004).

\subsection{As questões ambientais na ótica dos consumidores}

As questões ambientais são consideradas de maneiras diferentes pelos diversos atores da sociedade: governo, ONGs, empresas e consumidores. Governos e ONGs buscam cobrar ou colaborar para que sejam cada vez menores os impactos ambientais causados principalmente pelas empresas.

As empresas devem se preocupar com seu processo e o ciclo de vida de seus produtos. Os consumidores possuem uma visão diferente dos demais, nota-se que os atores anteriores têm suas ações direcionadas praticamente ao processo, e os consumidores se delimitam, na maioria das vezes, ao produto.

Quadro 1. Estágios de gestão ambiental das organizações.

\begin{tabular}{|c|c|c|}
\hline Autores & Estágio & Descrição \\
\hline \multirow{3}{*}{ Seiffert (2005) } & Estágio reativo & $\begin{array}{l}\text { O objetivo da empresa é ficar longe de problemas, buscando resolver } \\
\text { o mais breve possível os problemas ambientais e evitando custos } \\
\text { desnecessários. Quanto ao sistema de gestão ambiental, normalmente } \\
\text { é informal e repassado a especialistas, que trabalham para resolver } \\
\text { problemas específicos. }\end{array}$ \\
\hline & Estágio preventivo & $\begin{array}{l}\text { A empresa elabora um sistema de gestão ambiental mais formal, o qual } \\
\text { busca um determinado nível de conformidade, com várias necessidades } \\
\text { de gestão. }\end{array}$ \\
\hline & Estágio pró-ativo & $\begin{array}{l}\text { Busca gerenciar todos os riscos ambientais (e potenciais) da } \\
\text { organização, ou seja, não só os riscos já identificados, mas também os } \\
\text { riscos ainda não exigidos pelas normas. O principal objetivo é antecipar } \\
\text { os problemas, antes de ser necessário gerenciar as consequências deles. }\end{array}$ \\
\hline \multirow{3}{*}{$\begin{array}{l}\text { Rohrich e Cunha } \\
\qquad(2004)\end{array}$} & $\begin{array}{l}\text { Controle da poluição } \\
\left(1^{\circ} \text { nível }\right)\end{array}$ & Busca se adaptar às regulamentações ou exigências de mercado. \\
\hline & Prevenção ( $2^{\circ}$ nível $)$ & $\begin{array}{l}\text { É o que ocorre nas funções de produção, modificando quando } \\
\text { necessário os processos e até os produtos. }\end{array}$ \\
\hline & $\begin{array}{l}\text { Proatividade } \\
\left(3^{\circ} \text { nível }\right)\end{array}$ & $\begin{array}{l}\text { Quando há uma integração da gestão administrativa da organização } \\
\text { com o controle ambiental. }\end{array}$ \\
\hline \multirow{5}{*}{$\begin{array}{l}\text { Hunt e Auster } \\
\qquad(1990)\end{array}$} & Primeiro estágio & $\begin{array}{l}\text { Organizações que não possuem programas ambientais ou que } \\
\text { praticamente não existem devido a problemas orçamentários. }\end{array}$ \\
\hline & Segundo estágio & $\begin{array}{l}\text { Empresas que formam um pequeno staff centralizado, que pode } \\
\text { colaborar na resolução dos riscos ambientais. }\end{array}$ \\
\hline & Terceiro estágio & $\begin{array}{l}\text { Organizações que desenvolvem, no máximo, atividades ligadas à } \\
\text { prevenção de acidentes. Pode haver um departamento ambiental, } \\
\text { porém, não possui autoridade para realizar alterações no sistema. }\end{array}$ \\
\hline & Quarto estágio & $\begin{array}{l}\text { Organizações que gerenciam os problemas ambientais, os } \\
\text { departamentos ambientais possuem autoridade, são financiados e } \\
\text { desenvolvem ações como educação ambiental e treinamento com os } \\
\text { trabalhadores. }\end{array}$ \\
\hline & Quinto estágio & $\begin{array}{l}\text { Empresas pró-ativas, pois possuem programas efetivos na organização, } \\
\text { educam os funcionários, monitoram as operações, e são rápidas em } \\
\text { resolver os problemas. }\end{array}$ \\
\hline
\end{tabular}

Fonte: Sistematizado pelos autores (2010). 
No momento da compra, os consumidores avaliam a oferta e verificam, com base no valor oferecido, as características do produto. Não é diferente quando a oferta de um produto é direcionada a um público que se preocupa com as questões do meio ambiente.

Schultz et al. (2004), afirmam que os valores ambientais das pessoas estão relacionados com a natureza, atitudes ambientais específicas e preocupações, ou seja, cada um tem uma atitude em relação ao meio ambiente, conforme seus conceitos de relacionamento com o meio.

Os consumidores preocupados com a questão ambiental são definidos como aqueles que se caracterizam comprando produtos que tenham menor impacto ao meio ambiente quando eles têm uma oportunidade de comprar. Eles verificam as informações no rótulo da embalagem, procurando justificação ambiental para o produto (D'SOUZA, 2004).

Para Volsky et al. (1999), os consumidores ecológicos são aqueles que se sentem motivados a comprar produtos ecológicos, mesmo com preço mais elevado, em comparação com produtos semelhantes. Estes são os consumidores que fazem um esforço para comprar os produtos que favorecem o meio ambiente.

O consumidor ecológico prefere as embalagens recicláveis, dá preferência para embalagens com selos indicando a procedência ecologicamente correta do produto. Waldman e Schneider (2000) consideram que aquele opta pelas marcas que informam a composição da embalagem dos seus produtos, prefere utilizar produtos com refil, e não adquire produtos com isopor.

Verifica-se que a relação dos consumidores com a variável ambiental é praticamente envolvida no produto e não no processo das empresas. Um filtro instalado em uma empresa dificilmente será percebido pelo consumidor, este pode ser um item fiscalizado pelo governo.

Pode-se elencar as variáveis dos produtos que são analisadas pelos consumidores quando buscam por um produto ecologicamente correto:

- produtos ou embalagens fabricados com materiais reciclados;

- produtos ou embalagens recicláveis;

- produtos com selos ambientais;

- produtos que possuem fabricantes certificados pela ISO 14.001;

- produtos em que os fabricantes possuem ações ambientais;

- produtos de origem orgânica;

- produtos biodegradáveis; e

- produtos que consomem menos energia ou água.

Estas variáveis, se encontradas em um produto e oferecidas a um público que valoriza as questões ambientais, poderão proporcionar à organização algum tipo de vantagem competitiva na indústria em que opera.
O consumidor ecológico avalia a oferta de um produto com base no valor que possui sobre a variável ambiental. As organizações necessitam ter ciência do significado, das características, das formas e das possibilidades do termo valor, para dar início às atividades de entrega deste valor aos seus clientes.

Para Schultz et al. (2004), valor pode ser definido como importante objetivo de vida ou princípios, sendo a percepção específica de uma determinada situação para além do comportamento. Para estes autores, os valores indicam a fonte de informação para atitudes e comportamento ambiental.

$\mathrm{O}$ valor que os clientes atribuem aos produtos, relacionando seus benefícios e os custos de aquisição, é definido por Reinartz e Kumar (2003) como valor percebido. Os clientes tomam suas decisões de compra com base em uma expectativa de valor, assim, de acordo com sua percepção, dão preferência à organização que oferecer o valor desejado. Para Veludo-de-Oliveira e Ikeda (2005), o valor percebido é o ponto-chave com que as organizações devem se preocupar.

Para Azevedo, Lima Filho e Lucena (2002), os consumidores estão cada vez mais valorizando a oferta dos produtos das empresas que buscam minimizar a agressão ao meio ambiente. Ometto, Souza e Guelere Filho (2007) comentam que deve ser considerada a partir da análise do estágio da consciência dos consumidores, ou seja, até que ponto eles valorizam a oferta.

Um fator importante que deve ser considerado pelas organizações é o preço. A relação do preço do produto com o valor dos clientes pode trazer benefícios para a empresa. Existe a necessidade dos gestores desenvolverem habilidades para ofertar um produto, com base no valor para o cliente, a um preço condizente.

Conforme Veludo-de-Oliveira e Ikeda (2005), muitas organizações não levam em consideração as abordagens do tema valor quando precisam tomar decisões acerca de preço. O que para os autores é uma situação complicada, pois, quando se trata da precificação de produtos ou serviços, há uma grande dependência das percepções do cliente e consequentemente de seu valor percebido.

Conforme Nagle e Holden (2003), o valor de uso não é a chave para o desenvolvimento de uma estratégia efetiva de apreçamento, mas sim o valor econômico para o cliente, que significa o preço da melhor alternativa para ele (chamado de valor de referência) mais o valor de tudo quanto diferencia o produto dessa alternativa (chamado de valor de diferenciação).

Os profissionais de mercado há tempos exortam as empresas a estabelecer preços que reflitam o valor. Infelizmente, pelo fato de a definição de valor muitas vezes não ser clara, o apreçamento baseado em valor é 
por vezes rejeitado como não sendo prático (NAGLE; HOLDEN, 2003).

Uma estratégia de apreçamento baseada em valor envolve o gerenciamento das percepções dos clientes de modo pró-ativo para influenciar esse hiato entre preço pago e valor recebido. A análise do preço, segundo Nagle e Holden (2003), ou valor prêmio do produto ecológico na perspectiva do cliente torna-se necessária. No momento da compra, os clientes possuem alguns critérios que são utilizados para definir qual o produto a ser adquirido. São diversas as características dos produtos, incluindo a variável ambiental, porém o preço, na maioria dos casos, se torna fator fundamental neste processo de compra.

Desta forma, os clientes podem valorizar a questão ambiental, perceber a oferta de um produto ecológico, mas não o adquirir, pois seu preço não está adequado à sua realidade ou à sua condição. A empresa, mesmo tendo consumidores que valorizam e percebam seus produtos ecológicos, efetivamente não conseguirá realizar suas vendas, pois não haverá a demanda adequada.

Devido à baixa renda per capita de grande parte da população brasileira, poucos são sensíveis aos apelos ecológicos dos produtos. Mas, na visão de Maia e Vieira (2004), esta situação está mudando devido à divulgação mais frequente de apelos ambientais e programas de educação ambiental por parte de diferentes organizações e mesmo órgãos de mídia.

Churchill e Peter (2000) afirmam que 93\% dos consumidores americanos levam em conta o impacto ambiental no momento de tomarem suas decisões de compras. É interessante também outra consideração dos autores, na qual dois terços dos consumidores esperam que os produtos ecologicamente corretos não custem mais que os seus concorrentes.

Conforme Brasil (2008), 70\% dos pesquisados da capital paulista desistem de comprar produtos que agridem menos o meio ambiente se eles forem mais caros. Verifica-se a importância do fator preço, pois, se ele não for considerado, a pesquisa mostra que $41 \%$ dos consumidores possuem o hábito de comprar produtos com selo ambiental.

A relação de preço dos produtos com a renda dos consumidores é estreita. A pesquisa evidenciou que, dos consumidores com renda na faixa entre $\mathrm{R} \$ 5$ mil e $\mathrm{R} \$ 7$ mil, 22\% compram produtos ecológicos mesmo sendo mais caros. Esta porcentagem sobe para $48 \%$ se a faixa for de $\mathrm{R} \$ 7$ mil a $\mathrm{R} \$ 10$ mil.

O nível de conhecimento dos consumidores quanto às questões ambientais aumenta com o passar do tempo devido à globalização da informação. Para Medeiros e Silva (2003), os consumidores estão valorizando produtos e serviços ecologicamente corretos, pois há um despertar de preservação em meio aos constantes acidentes e incidentes ecológicos. Porém, além do fator preço, conforme Brasil (2008), a pesquisa aponta que o nível de informação sobre o assunto ainda é deficiente, sendo que os mais jovens são os mais bem informados, porém os que menos procuram tais produtos.

A aceitação dos produtos ecológicos é maior quanto mais idade tiver o consumidor, a faixa de idade de 41 a 50 anos é a que mais procura os produtos ecológicos para a compra. Dos entrevistados, $54 \%$ dos consumidores de produtos ecológicos são homens e $29 \%$ são mulheres, mostrando que os homens possuem mais consciência ambiental.

Sabe-se que para um consumidor valorizar um produto ecológico, ele necessita ter consciência ambiental. Porém, para que as empresas possam obter sucesso nesta área, os consumidores necessitam possuir a consciência, valorizar a oferta e principalmente efetivar a compra do produto ecológico.

\section{Modelo proposto}

Conforme fundamentado, existe a necessidade de uma gestão ambiental, em que investimentos precisam ser realizados. Verificou-se também que, sob a visão mercadológica, os clientes valorizam produtos ecológicos e não processos adequados quanto ao meio ambiente. Desta forma, para que os tomadores de decisão invistam na adequação de sua gestão ambiental, tomando como base o valor para os clientes, é necessário identificar o limite dos recursos que serão injetados.

Para a construção do modelo proposto, foram adaptadas as seguintes técnicas científicas: Método de Valoração Contingente (MVC); Escala de Thurstone; Instrumento de Mensuração do Grau de Consciência Ambiental, do Consumo Ecológico e dos Critérios de Compra dos Consumidores; Análise Conjunta; e Valor Presente Líquido (VPL).

\subsection{Apresentação do modelo proposto}

As etapas para o desenvolvimento do modelo proposto com suas respectivas saídas, adaptando as técnicas citadas, estão apresentadas na Figura 1.

\subsection{Descrição das etapas do modelo proposto}

\subsubsection{Primeira etapa - Identificação do valor para os consumidores dos produtos ecológicos}

A primeira etapa do modelo proposto consiste na verificação do valor e da preferência de compra dos consumidores em relação aos produtos ecologicamente corretos. Esta etapa serve como fonte de informações ao pesquisador para verificar se os consumidores valorizam as questões ambientais, além de identificar 


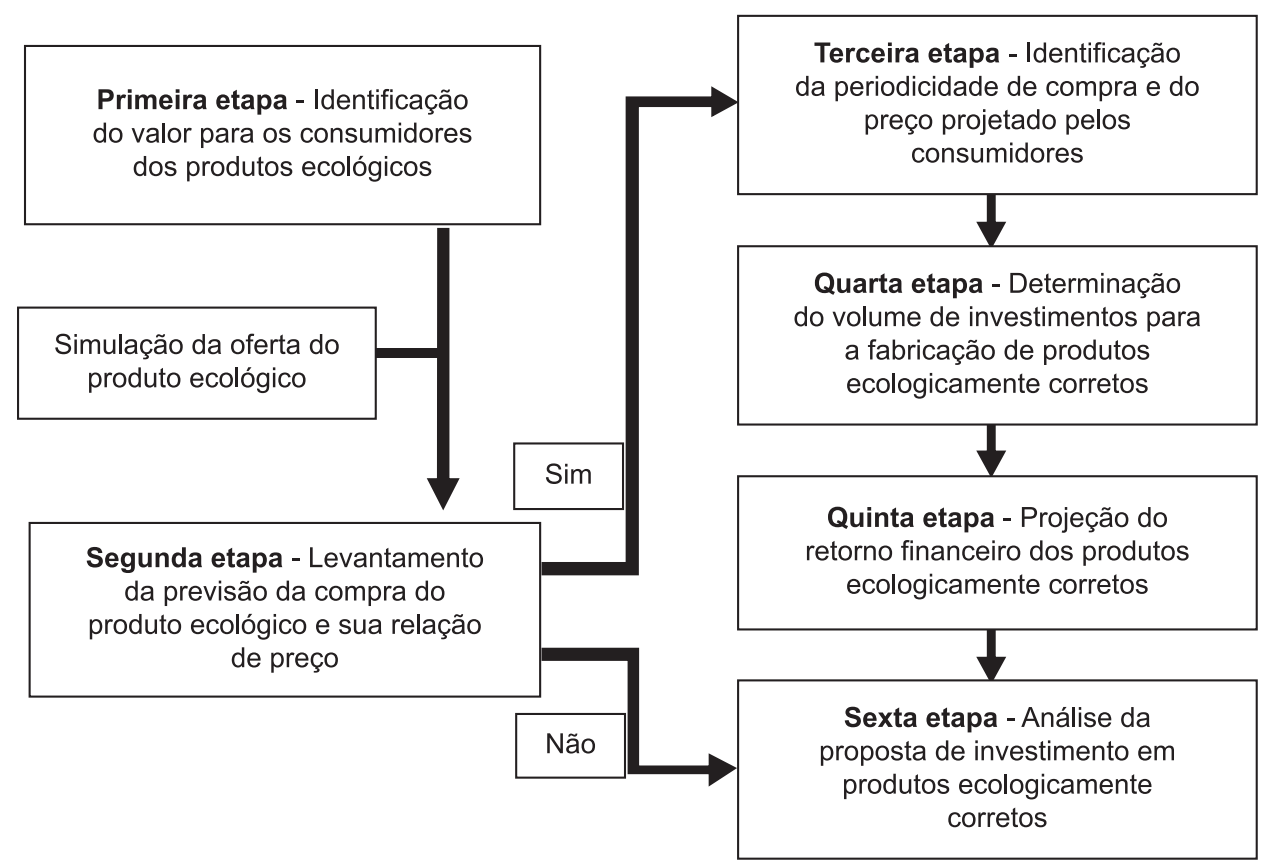

Figura 1. Fluxograma do desenvolvimento do modelo proposto.

o perfil do consumidor ecológico ou daquele que valoriza os produtos ecológicos.

Para identificar o que é valorizado nos produtos ecológicos, foi construído um questionário, conforme o Quadro 2, contendo doze questões. Este questionário está relacionado às variáveis dos produtos que são analisadas pelos consumidores ecológicos.

As questões de 1 a 7 buscam identificar o valor para o consumidor ecologicamente correto. As questões de 8 a 11 foram elaboradas buscando informações complementares dos entrevistados, seu perfil, com a finalidade de dar maior suporte à avaliação e às recomendações a serem feitas na sexta etapa. $\mathrm{O}$ pesquisador deve solicitar aos entrevistados que, ao responder ao questionário, devem assinalar somente uma resposta para cada pergunta.

Depois do pesquisado responder as questões de 1 a 7 , deve ser lhe solicitado que distribua 10 pontos (de 1 a 10), na coluna intitulada 'Grau de Preferência', apenas naquelas questões em que foi assinalada a resposta a. O perfil do entrevistado e o perfil do consumidor que valoriza um produto ecologicamente correto serão encontrados com a tabulação das questões de 8 a 11.

Ao encerrar esta etapa, o pesquisador possuirá informações sobre quais características dos produtos ecológicos os consumidores valorizam e, entre estas características, seu grau de preferência, e o perfil dos consumidores que dão importância aos produtos ecologicamente corretos. Estas informações serão utilizadas na sexta etapa deste modelo, para complementar a análise da proposta de investimento em produtos ecologicamente corretos.

\subsubsection{Segunda etapa - Levantamento da previsão da compra do produto ecológico e sua relação de preço}

Esta etapa do modelo consiste na simulação da oferta do produto ecológico aos consumidores. $\mathrm{O}$ pesquisador deverá ter como base as informações levantadas na primeira etapa, ou seja, quais características são valorizadas e qual o grau de preferência dos consumidores pesquisados. Desta forma, será possível verificar se os consumidores poderão comprar e o quanto estão dispostos a pagar por produtos ecologicamente corretos. Esta etapa foi elaborada com base no Método de Valoração Contingente (MVC).

O pesquisador deverá ter disponível três produtos, o da empresa pesquisada e dois dos concorrentes. A finalidade de disponibilizar mais dois produtos de concorrentes é a de, além de não deixar evidente a intenção da pesquisa, verificar as preferências dos consumidores no momento da compra.

Se não for possível ter à disposição o produto fisicamente, poderá ser utilizado algum material ilustrativo, podendo ser foto ou folder, que contenha informações dos produtos como: nome, formato ilustrativo e algumas características particulares, como se o entrevistado estivesse em um supermercado e verificasse tais características na embalagem. 
O pesquisador deverá apresentar o produto pesquisado, alegando que ele contempla todas aquelas características valorizadas, identificadas na etapa anterior. Depois desta apresentação, deve ser solicitado aos consumidores que classifiquem, conforme suas preferências de compra, os produtos apresentados, e que respondam as questões do Quadro 3, o qual possui cinco opções de resposta, embasado na Escala de Thurstone. Depois da aplicação das questões do Quadro 3, para identificar a preferência de compra dos consumidores, o pesquisador deve utilizar o Quadro 4, o qual foi adaptado do Instrumento de mensuração do grau de consciência ambiental, do consumo ecológico e dos critérios de compra dos consumidores, proposto por Bertolini e Possamai (2005).

Para cada alternativa são dados pesos correspondentes, sendo $\mathrm{A}$ - zero, $\mathrm{B}-2$ pontos, $\mathrm{C}-4$ pontos, $\mathrm{D}-6$ pontos e $\mathrm{E}-8$ pontos. Depois de aplicar a pesquisa, utilizam-se os dados adquiridos para transformá-los em informação. Para elaboração dos cálculos, o pesquisador utilizará três vezes o Quadro 4, uma para cada produto apresentado. Verificando o registro das indicações efetuado no momento da entrevista, o pesquisador deve alocar a quantidade de vezes que o produto apresentado foi colocado em cada critério na coluna a. Multiplicando a quantidade de respostas pelos respectivos pontos (b) indicados anteriormente, tem-se um resultado $(\mathrm{a} \times \mathrm{b})$ para cada alternativa. Somam-se todos os resultados (c) e, por último, divide-se o resultado obtido na operação passada pela quantidade de entrevistados (d).

Obtém-se com estes cálculos um valor (e) que mostrará como está a preferência dos consumidores em relação aos produtos pesquisados, conforme o Quadro 5, o qual foi adaptado do Instrumento de mensuração do grau de consciência ambiental, do consumo ecológico e dos critérios de compra dos consumidores, de Bertolini e Possamai (2005).

Como o valor obtido para identificar o resultado da preferência do consumidor (e) é a média das respostas com seus respectivos pesos, existe a possibilidade das frequências de respostas estarem dispersas, e quanto maior for esta dispersão, maior será a distância entre a média com cada resposta. Por isso, é necessário o cálculo do desvio padrão para medir a dispersão das respostas em relação à média, sendo útil no momento da avaliação da preferência do consumidor. Conforme o Quadro 5, se o valor obtido nos cálculos for de zero a 0,99 , verifica-se que os consumidores, apesar de valorizar as características

Quadro 2. Questões sobre valor para o consumidor e perfil do entrevistado.

\begin{tabular}{|c|c|c|c|c|}
\hline \multicolumn{4}{|c|}{ Questões } & Grau de Preferência \\
\hline \multicolumn{4}{|c|}{ 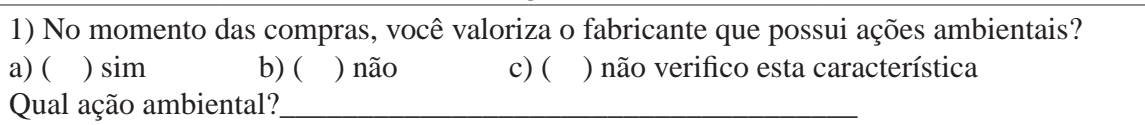 } & \\
\hline \multicolumn{4}{|c|}{ 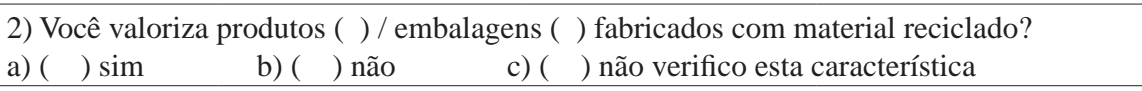 } & \\
\hline \multicolumn{4}{|c|}{ 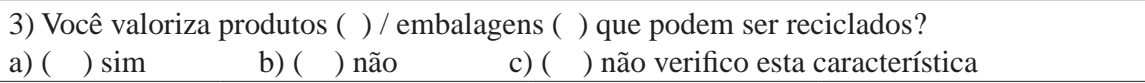 } & \\
\hline \multicolumn{4}{|c|}{ 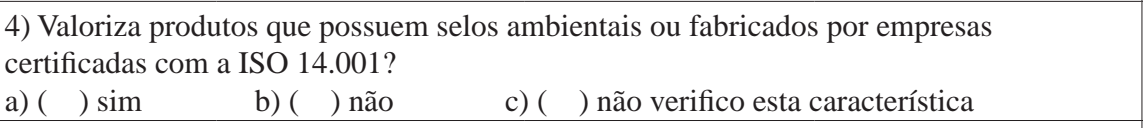 } & \\
\hline \multicolumn{4}{|c|}{$\begin{array}{l}\text { 5) Você dá importância a produtos orgânicos? } \\
\begin{array}{lll}\text { a) }\left(\begin{array}{ll}) \\
\text { sim }\end{array}\right. & \text { b) ( ) não } & \text { c) ( ) não verifico esta característica }\end{array}\end{array}$} & \\
\hline \multirow{2}{*}{\multicolumn{4}{|c|}{ 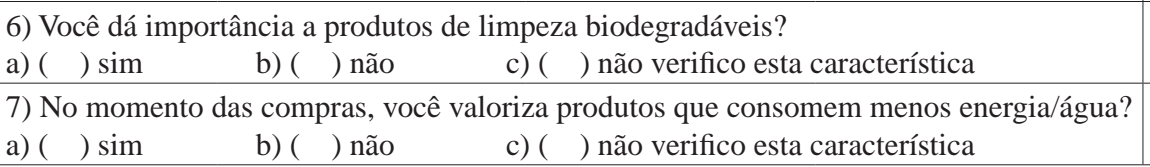 }} & \\
\hline & & & & \\
\hline \multicolumn{5}{|c|}{ 8) Qual o seu nível de escolaridade? } \\
\hline $\begin{array}{l}\text { ( ) Ensino } \\
\text { Fundamental }\end{array}$ & ( ) Ensino Médio & ( ) Ensino Superior & $\begin{array}{l}\text { ( ) Pós-graduação } \\
\text { (especialização) }\end{array}$ & $\begin{array}{l}\text { ( ) Pós-graduação } \\
\text { (Mestrado - Doutorado) }\end{array}$ \\
\hline \multicolumn{5}{|c|}{ 9) Qual é a sua renda familiar? } \\
\hline $\begin{array}{l}\text { ( ) Até um } \\
\text { salário mínimo }\end{array}$ & $\begin{array}{l}\text { ( ) Mais de um a } \\
\text { cinco salários mínimos }\end{array}$ & $\begin{array}{l}\text { ( ) Mais de cinco a } \\
\text { dez salários mínimos }\end{array}$ & $\begin{array}{l}\text { ( ) Mais de dez a } \\
\text { quinze salários mínimos }\end{array}$ & $\begin{array}{l}\text { ( ) Mais de quinze } \\
\text { salários mínimos }\end{array}$ \\
\hline \multicolumn{5}{|c|}{ 10) Qual a sua idade? } \\
\hline ( ) até 24 anos & ( ) de 25 a 34 anos & ( ) de 35 a 49 anos & ( ) Acima dos 50 & \\
\hline \multicolumn{5}{|l|}{ 11) Sexo } \\
\hline ( ) Masculino & ( ) Feminino & & & \\
\hline
\end{tabular}


Quadro 3. Critérios da preferência de compra dos consumidores.

\begin{tabular}{|l|l|}
\hline a) ( ) & Não compro este produto independente de seu preço. \\
\hline b) ( ) & Compro, somente se este produto estiver com preço abaixo de seus similares. \\
\hline c) ( ) & Compro, se este produto estiver no mesmo preço que os seus similares. \\
\hline d) ( ) & Compro este produto, mesmo se estiver com preço maior que os seus similares. \\
\hline e) ( ) & Compro este produto independente de seu preço. \\
\hline
\end{tabular}

Quadro 4. Cálculos para projeção da preferência de compra dos consumidores.

\begin{tabular}{|c|c|c|}
\hline (a) Quantidade de respostas & (b) Pontuação & (a $\times$ b) Resultado \\
\hline A & 0 & \\
\hline B & 2 & \\
\hline C & 4 & \\
\hline D & 6 & \\
\hline E & 8 & \\
\hline \multicolumn{2}{|c|}{ (c) Soma dos resultados } & \\
\hline \multicolumn{2}{|c|}{ (e de entrevistados c/d) Resultado da preferência } \\
\hline
\end{tabular}

Quadro 5. Projeção da preferência de compra dos consumidores.

\begin{tabular}{|c|l|}
\hline Resultado & \multicolumn{1}{|c|}{ Preferência de compra } \\
\hline Zero a 0,99 & Não comprarão o produto. \\
\hline 1 a 2,99 & Comprarão o produto, desde que seu preço seja inferior aos demais. \\
\hline 3 a 4,99 & Comprarão o produto, desde que seu preço seja igual aos demais. \\
\hline 5 a 6,99 & Comprarão o produto e pagarão um pouco a mais por ele. \\
\hline 7 a 8 & Comprarão o produto independente de seu preço. \\
\hline
\end{tabular}

do produto, não o comprarão. Se o resultado for de 1 a 2,99, estima-se que os consumidores comprarão o produto pesquisado, desde que seu preço esteja inferior aos de seus concorrentes. De 3 a 4,99, poderá ser previsto que os consumidores comprarão o produto, desde que seu preço esteja igual aos outros produtos semelhantes.

Se for encontrado um número de 5 a 6,99 , verifica-se que os consumidores comprarão o produto e estarão dispostos a pagar um pouco a mais por ele. Finalmente, se for encontrado um resultado de 7 a 8 , estima-se que os consumidores valorizam a oferta do produto, estão dispostos a comprar e a pagar o preço proposto.

Se alguns pesquisados indicarem várias características valorizadas (primeira etapa), o pesquisador deverá realizar outras simulações, iniciando com as características com maior grau de preferência.

Com o término desta etapa, o pesquisador possuirá a informação se os consumidores irão ou não comprar o produto ecologicamente correto proposto, e qual a disposição de compra em relação ao preço do produto e dos concorrentes. Para isso, o pesquisador deverá verificar o valor obtido pelo cálculo, tendo como base a escala de 0 a 8 , ou visualizando no quadro de projeção de preferência do consumidor.
Se o resultado encontrado nessa etapa mostrar que os consumidores não comprarão o produto, as próximas etapas não serão necessárias, devendo o pesquisador analisar o perfil dos pesquisados e concluir o estudo. Os resultados encontrados nesta etapa serão utilizados em conjunto com os resultados encontrados nas etapas seguintes, os quais mostram o preço projetado do produto e o retorno financeiro projetado com a oferta. Assim, será possível analisar a proposta de investimentos em produtos ecologicamente corretos.

\subsubsection{Terceira etapa - Identificação da periodicidade de consumo e do preço projetado pelos consumidores}

A terceira etapa do modelo proposto refere-se à identificação da periodicidade de consumo dos consumidores em relação ao produto pesquisado, bem como a identificação de seu preço projetado pelos consumidores.

O objetivo de investigar a periodicidade de consumo do produto e seu preço projetado é de utilizar esta informação para a projeção da possível receita financeira, com a oferta do produto ecologicamente correto.

Por ser um modelo genérico, dependendo do produto que será analisado, o consumo poderá ser 
realizado diariamente, semanalmente, mensalmente, anualmente, entre outros. Assim, deverá ser solicitada ao consumidor a periodicidade do consumo do objeto da pesquisa. Somados os resultados, obtém-se o Q.C.I. - Quantidade de Consumo Individual da amostra.

Para a determinação do preço projetado, deve ser utilizado o instrumento 'Identificação da Preferência de Preço', conforme o Quadro 6, o qual foi adaptado do modelo de múltiplos fatores da técnica Análise Conjunta.

$\mathrm{O}$ instrumento deve conter como título das colunas a seguinte sequência: Conceito, Marca, Ambientalmente Correto, Característica A e Característica B, além de Preço e Escolha. As características A e B são aquelas que o pesquisador identifica nos outros dois produtos similares ao objeto do estudo.

Em seu centro, devem estar indicados os produtos utilizados na segunda etapa, e seus respectivos preços de venda de forma decrescente, salvo o produto 'ambientalmente correto' que deve ser indicado o produto atual da empresa em estudo.

As demais linhas do instrumento devem ser preenchidas com as características do produto 'ambientalmente correto'. Para preenchimento da coluna 'preço', o pesquisador deverá ter como base, os preços dos produtos já dispostos no centro do instrumento. Para determinação dos preços acima do centro, deve ser acrescida ao preço de venda a taxa proveniente da variação dos preços dos três produtos utilizados na segunda etapa, e proceder da mesma forma para os preços abaixo do centro. Sugere-se que o instrumento tenha vinte e três linhas, dez acima dos três produtos do centro e dez abaixo deles.

A utilização deste instrumento deve possuir como base a classificação alcançada no Quadro 3 - Critérios da Preferência de Compra dos Consumidores, da segunda etapa. Se o pesquisado indicar a alternativa $\mathbf{b}$
'Compro, somente se este produto estiver com preço abaixo de seus semelhantes', o pesquisador deve dar orientação para que a escolha do preço se inicie abaixo dos preços dos produtos indicados.

Se o pesquisado indicar a alternativa c 'Compro, se este produto estiver no mesmo preço que os seus semelhantes', o pesquisado deve realizar sua escolha do preço entre os produtos indicados.

Se o pesquisado indicar a alternativa d 'Compro este produto, mesmo se estiver com preço maior que os seus semelhantes', o pesquisador deve dar orientação para que a escolha do preço se inicie acima dos preços dos produtos indicados. Se a indicação for a alternativa e "Compro este produto independente de seu preço', deve ser sugerido o primeiro preço do instrumento (conceito 1) e, posteriormente, questionar abertamente qual o preço adequado ao produto.

Para identificar o preço projetado pelos consumidores para o produto ecologicamente correto, o pesquisador deverá utilizar o Quadro 7, o qual foi adaptado do Instrumento de mensuração do grau de consciência ambiental, do consumo ecológico e dos critérios de compra dos consumidores, proposto por Bertolini e Possamai (2005).

Se os consumidores indicarem na segunda etapa que compram o produto e pagam mais por ele, e indicarem abertamente um preço maior que o indicado no conceito 1, o pesquisador deve, antes de utilizar o Quadro 7, efetivar a média do preço destes consumidores e alocá-lo na coluna 'resultado' do conceito 'aberta'.

Para elaboração dos cálculos, o pesquisador deve alocar a quantidade de vezes que cada preço foi mencionado na coluna número de respostas (a). Multiplicando a quantidade de respostas pelos respectivos preços (b), tem-se um resultado $(a \times b)$ para cada alternativa. Somam-se todos os resultados (c) e, por último, divide-se o resultado obtido na operação

Quadro 6. Identificação da preferência de preço.

\begin{tabular}{|c|c|c|c|c|c|c|}
\hline Conceito & Marca & Ambient. Correto & Caract. A & Caract. B & Preço R\$ & Escolha \\
\hline 1 & & & & & & \\
\hline 2 & & & & & & \\
\hline 3 & & & & & & \\
\hline
\end{tabular}

Quadro 7. Cálculos para identificação da preferência de preço.

\begin{tabular}{|c|c|c|c|}
\hline Conceito & (a) $n^{0}$ Respostas & (b) Preço (R\$) & $(\mathbf{a} \times \mathbf{b})$ Resultado \\
\hline \multicolumn{4}{|l|}{ Aberta } \\
\hline \multicolumn{4}{|l|}{1} \\
\hline \multicolumn{4}{|l|}{2} \\
\hline \multicolumn{4}{|l|}{3} \\
\hline \multicolumn{3}{|c|}{ (c) Soma dos resultados } & \\
\hline \multicolumn{3}{|c|}{ (d) $n^{\circ}$ de entrevistados } & \\
\hline \multicolumn{3}{|c|}{ (e = c/d) Projeção do preço (P.P.) } & \\
\hline
\end{tabular}


passada pela quantidade de entrevistados (d). Obtém-se com estes cálculos um valor (e) que mostrará a projeção do preço (P.P.) aceitável do produto ecologicamente correto indicado pelos consumidores.

Ao encerrar esta etapa, o pesquisador possuirá informações tais como a quantidade de produtos consumidos periodicamente pela amostra pesquisada e a projeção do preço aceitável do produto ecologicamente correto indicado pelos consumidores. Informações estas que serão utilizadas na quinta etapa, para elaborar a projeção do retorno financeiro dos produtos ecologicamente corretos e consequentemente atingir o objetivo geral deste trabalho.

\subsubsection{Quarta etapa - Determinação do volume de investimentos para a fabricação de produtos ecologicamente corretos}

Esta etapa consiste em determinar o valor do investimento necessário para a fabricação de produtos ecológicos. Com base no que os clientes valorizam em produtos ecológicos e se eles irão comprar e pagar mais por ele, verifica-se qual o custo das transformações necessárias na empresa para ser investido.

Por se tratar de um modelo abrangente e das diversas possibilidades que podem ser encontradas para adequação dos produtos em relação ao meio ambiente, nesta etapa o pesquisador deverá analisar na organização em estudo, com base no valor que os consumidores possuem, o impacto nos custos com as devidas alterações.

Para efetivação desta etapa, o pesquisador deve identificar as especificações dos elementos que deverão ser alterados, separando-os em diretos e indiretos, e realizar uma pesquisa de mercado com no mínimo três empresas que atendam às mudanças necessárias nos produtos, observando as especificidades das organizações.

Realizados os orçamentos, o pesquisador deve desenvolver um quadro indicativo da média de valores para implantação das alterações. O Quadro 8 deve necessariamente conter todos os elementos que irão compor a alteração do produto, podendo abranger os insumos, serviços, maquinário, mão de obra especializada, estrutura física, tecnologia, dentre outros que possam surgir. Ao final das cotações, o pesquisador deverá calcular a média individual e total, a qual será utilizada para levantar o custo adicional por produto. Os custos diretos deverão ser adicionados ao atual preço de venda do produto. Também deverá ser identificado em valores o I.P.E. - Investimento para formar o Produto Ecológico (custos indiretos) - para atender às exigências de alterações embasadas no valor para os consumidores.

A presente etapa é necessária, pois, com a determinação dos valores do I.P.E, é possível realizar a estimativa de retorno do investimento. Ao encerrar esta etapa, o pesquisador possuirá informações relevantes que serão utilizadas na sexta etapa do modelo, na qual será presumível estimar qual será o retorno para cada real investido na formação do produto ecologicamente correto.

\subsubsection{Quinta etapa - Projeção do retorno financeiro dos produtos ecologicamente corretos}

A quinta etapa do modelo proposto, embasada na técnica Valor Presente Líquido (VPL), consiste na projeção do retorno financeiro que a organização poderá obter se decidir investir alguma soma de recursos para tornar seus produtos ecologicamente corretos.

Para realizar a projeção, o pesquisador deverá utilizar os resultados da terceira etapa: identificação da periodicidade de consumo e do preço projetado pelos consumidores quanto aos produtos, bem como, da quarta etapa: determinação dos investimentos necessários para a formação do produto em ecologicamente correto.

De acordo com a literatura, o consumidor ecologicamente correto é aquele que paga mais por um produto ecológico. Embasado nessa afirmação, decidiu-se utilizar como retorno financeiro unitário, a

Quadro 8. Cotação dos valores para fabricação de produtos ecologicamente corretos.

\begin{tabular}{|c|c|c|c|c|c|}
\hline Diretos & Especificações & Fornecedor 1 & Fornecedor 2 & Fornecedor 3 & Média \\
\hline & & & & & \\
\hline & & & & & \\
\hline & & & & & \\
\hline Total & & & & \\
\hline & & & & & \\
\hline & & & & & \\
\hline \multicolumn{2}{|c|}{ Total } & & & & \\
\hline
\end{tabular}


diferença entre o preço projetado pelos consumidores e o preço atual do produto praticado pela empresa.

Para projetar o valor do retorno financeiro, devem ser utilizadas, sucessivamente, as seguintes equações. A primeira, equação 1, trata da Projeção da Valorização Unitária (P.V.un.).

$$
\text { P.P. }-(\text { P.A. + C.D. })=\text { P.V.un. }
$$

em que:

P.P. $=$ Preço Projetado;

P.A. = Preço Atual praticado pela organização;

C.D. = Custos Diretos do produto ecológico; e

P.V.un. = Projeção da Valorização Unitária.

Para a resolução dessa primeira equação, o pesquisador deve subtrair do Preço Projetado encontrado na quarta etapa (P.P.), o somatório do Preço Atual praticado pela organização (P.A.) com os Custos Diretos para fabricação do produto ecológico (C.D.). Se houver a presença de um distribuidor no processo de venda, a subtração do P.P. deverá ser realizada no somatório do P.A., C.D. e da margem de lucro do distribuidor. Com isso será encontrado o P.V.un., que será utilizado na equação 2: Projeção da Valorização Total periódica (P.V.T.p.), conforme a periodicidade de consumo verificada na terceira etapa.

$$
\text { P.V.un. } \times \text { Q.C.I. } \times \mathrm{N}=\text { P.V.T.p. }
$$

em que:

P.V.un. = Projeçã o da Valorização Unitária;

Q.C.I. = Quantidade de Consumo Individual;

$\mathrm{N}$ = Número de consumidores da organização; e

P.V.T.p. $=$ Projeção da Valorização Total periódica.

Para a resolução da Equação 2, o pesquisador deve multiplicar o P.V.un. com a Quantidade de Consumo Individual encontrada na terceira etapa (Q.C.I.) e com a quantidade de consumidores que a organização possui $(\mathrm{N})$. Como resultado desse cálculo, será encontrado o P.V.T.p.

Para concluir a viabilidade do investimento, é preciso multiplicar o período do projeto pela projeção periódica de retorno financeiro, então é necessário considerar o valor do dinheiro no tempo. A Equação 3 trata da Projeção da Valorização Total do Período Descontado (P.V.T.des.), que é a fórmula do 'Valor Presente de uma Renda Imediata', base da técnica VPL.

$$
\text { P.V.T.m. } \times \frac{1-(1+1)^{-n}}{\mathrm{i}}=\text { P.V.T.des. }
$$

em que:

P.V.T.p. $=$ Projeção da Valorização Total periódica;

$\mathrm{n}=$ Período do projeto;

$\mathrm{i}=$ Taxa do custo do capital ou da rentabilidade mínima exigida; e

P.V.T.des. = Projeção da Valorização Total do Período Descontado.
Além do P.V.T.p., identificado anteriormente, o pesquisador deverá identificar o período que o projeto terá de vida útil (n). Para a realização deste cálculo, o pesquisador deverá identificar a taxa de rentabilidade mínima exigida pela organização em seus projetos, ou o custo do capital utilizado por ela (i).

O resultado desse cálculo será o P.V.T.des., ou seja, como se todo o retorno financeiro do investimento para formação de produtos ecologicamente corretos, entrasse no caixa da organização no primeiro momento do projeto.

A última equação desta etapa é a Equação 4: Retorno Financeiro Projetado para cada R \$ Investido (R.F.R \$ in.).

$$
\frac{\text { P.V.T.des. }}{\text { I.P.E. }}=\text { R.F.R\$in. }
$$

em que:

P.V.T.des. = Projeção da Valorização Total do Período Descontado;

I.P.E. = Investimento para formar o Produto Ecológico; e

R.F.R\$ in. $=$ Retorno Financeiro Projetado para cada R\$ Investido.

Para a resolução da Equação 4, o pesquisador deve dividir o P.V.T.des. pelo I.P.E. encontrado na quarta etapa desse modelo. Com o resultado dessa divisão, será encontrado o R.F.R \$ in. para cada R\$ investido na formação do produto ecologicamente correto. Ao findar essa etapa, o pesquisador terá definido qual é o retorno para cada real investido no produto ecologicamente correto.

\subsubsection{Sexta etapa - Análise da proposta de investimento em produtos ecologicamente corretos}

A sexta e última etapa do modelo proposto consiste em analisar a viabilidade do investimento em produtos ecologicamente corretos. Para a realização da análise, serão necessários os resultados da segunda, quarta e principalmente da quinta etapa, da qual pode ser realizada a primeira análise da proposta, conforme as considerações do Quadro 9. Conforme o Quadro 9, se R.F.R\$ in. for menor que 1 , não há viabilidade financeira no investimento, pois os valores que deverão ser investidos serão maiores que o retorno esperado com a oferta do produto ecológico. Se R.F.R\$ in. encontrada for igual a 1 , não haverá projeção de lucro nem prejuízo, devendo os gestores da organização decidir sobre a execução do projeto, pois a questão ambiental não deve ser desconsiderada, mesmo não havendo retorno financeiro, a empresa não ficará sem ações ambientais no mercado. A R.F.R \$ in. maior que 1 representa que é projetado retorno financeiro no projeto de investimento. 
Quadro 9. Situações para análise da viabilidade do investimento.

\begin{tabular}{|c|l|}
\hline $\begin{array}{c}\text { Situação do retorno financeiro projetado } \\
\text { para cada R\$ investido }\end{array}$ & \multicolumn{1}{c|}{ Viabilidade do investimento } \\
\hline R.F.R in. $<1$ & Não há viabilidade financeira no investimento. \\
\hline R.F.R in. $=1$ & Ponto de Equilíbrio do Investimento. \\
\hline R.F.R in. $>1$ & Há viabilidade financeira no investimento. \\
\hline
\end{tabular}

Porém, não será adequado utilizar somente o Quadro 9 para a análise. Observado o modelo, podem-se identificar cinco possíveis possibilidades, as quais seguem com as devidas recomendações:

- Primeira Possibilidade: Se na segunda etapa o pesquisador encontrar como resultado que os consumidores não comprarão o produto ecologicamente correto, deverão ser verificadas, além da classificação dos outros produtos, quais características são valorizadas. Assim, poderão ser explicados os motivos pelos quais os consumidores não aceitarão a oferta. Nessas condições, a empresa deverá utilizar seus meios de comunicação e divulgação no mercado para desenvolver ações de educação ambiental, buscando a formação da consciência ambiental dos consumidores para despertar o interesse por produtos ecológicos;

- Segunda Possibilidade: Se na segunda etapa for identificado que os consumidores comprarão o produto, desde que seu preço seja inferior aos demais, provavelmente o pesquisador encontrará na sexta etapa um retorno negativo a cada recurso investido. Essa situação poderá ser explicada analisando as características valorizadas por eles, identificadas na terceira etapa. As ações necessárias nessa possibilidade são: a utilização de seus meios de comunicação e divulgação no mercado, para desenvolver ações de educação ambiental, buscando o crescimento da consciência ambiental dos consumidores, para o posterior consumo de produtos ecológicos. Além de buscar, com a formação ecológica da organização, a redução dos custos diretos e indiretos, procurando alcançar rentabilidade, pois os consumidores só comprarão se o produto estiver com preço baixo;

- Terceira Possibilidade: Se os consumidores indicarem que comprarão o produto, desde que seu preço seja igual aos demais, o pesquisador poderá encontrar na quinta etapa um baixo retorno a cada recurso investido, que poderá ser positivo ou negativo. As ações necessárias nessa possibilidade são equivalentes à situação anterior, ou seja, a utilização de seus meios de comunicação e divulgação com o mercado, para desenvolver ações de educação ambiental, buscando o fortalecimento da consciência ambiental dos consumidores, para o desenvolvimento do consumo e do valor aos produtos ecológicos. Outra recomendação é a busca da redução dos custos diretos e indiretos da organização, procurando alcançar maior rentabilidade, pois os consumidores só comprarão se o produto estiver com preço paralelo aos seus semelhantes;

- Quarta Possibilidade: Se na segunda etapa for identificado que os consumidores comprarão o produto e pagarão um pouco mais por ele, o pesquisador poderá encontrar na sexta etapa um retorno positivo ou negativo. Recomenda-se novamente a utilização dos meios de comunicação e divulgação da empresa, para desenvolver ações de educação ambiental, buscando a maturação da consciência ambiental dos consumidores, e consequente disposição de compra por produtos ecológicos pelos valores solicitados; e

- Quinta Possibilidade: Se os consumidores mostrarem o interesse por comprar o produto independente de seu preço, o pesquisador poderá identificar um retorno positivo a cada real investido, sendo viável o investimento em produtos ecologicamente corretos. Neste caso, a empresa deverá realizar ampla divulgação e promoção da oferta do produto ecológico. Por fim, é recomendado também conhecer quem são os consumidores que compram e pagam a mais pelo produto ecológico (identificados no perfil traçado na primeira etapa). Sabendo quem são os consumidores ecológicos, poderá ser feita uma análise personalizada desses, identificando o R.F.R \$ in. desse público.

\subsection{Implementação do modelo proposto}

Para ser possível implementar o modelo proposto, o pesquisador deve identificar a empresa que pretende investir recursos financeiros, para tornar seu produto ecologicamente correto. Depois de identificar a empresa, deverá ser escolhido o (s) produto (s) que será (serão) objeto de toda a aplicação. 
Para que as etapas possam ser realizadas, é necessário evidenciar a amostra que será pesquisada. Depois de calculado e identificado o número de entrevistados necessários para a realização do estudo, o pesquisador pode iniciar a aplicação do modelo, que consiste em três momentos: a aplicação dos questionários, o levantamento dos valores de investimentos na organização em estudo e a elaboração dos cálculos e análises financeiras.

O questionário da primeira etapa deve ser aplicado, sem mencionar o produto da organização em estudo. Somente quando forem apresentadas as questões da segunda etapa, é que deverá ser divulgado o produto em estudo, alegando que possui todas as características valorizadas pelo pesquisado no questionário anterior. Na sequência, deverá ser verificada a periodicidade de compra do produto pesquisado, e por último utilizar o questionário da terceira etapa para identificar o preço projetado pelos consumidores.

Depois da aplicação dos questionários com toda a amostra, o segundo momento da aplicação do modelo proposto consiste nas visitas à organização em estudo, nos fornecedores, certificadores entre outros, para verificar o custo das transformações necessárias para realização do investimento, conforme as orientações já descriminadas na quarta etapa.

Por último, para a elaboração dos cálculos e análises financeiras, o pesquisador deverá aplicar as fórmulas apresentadas na quinta etapa e analisar a viabilidade do investimento, com as orientações da sexta etapa do modelo proposto.

\section{Considerações finais}

A literatura apresenta a necessidade de investimentos na área de gestão ambiental das organizações, alegando que aquelas que investirem alcançarão vantagens competitivas. Porém, verifica-se a necessidade de ferramentas que possam auxiliar os gestores para a tomada de decisão sobre onde, como e quanto investir. E ainda, os investidores buscam saber se seus recursos serão bem empregados nas organizações. O modelo proposto, composto por seis etapas, foi elaborado com base na literatura, em modelos existentes e em pesquisas sobre as questões ambientais e retorno de investimentos.

Por possuir várias etapas, o modelo, em alguns momentos, possui alguns detalhes que podem trazer certa dificuldade para o pesquisador que o estiver aplicando. O primeiro detalhe que deve ser observado encontra-se na segunda etapa, quando deve ser solicitado aos pesquisados que distribuam 10 pontos como grau de importância nas questões ambientais.

Outro aspecto que deve ser considerado está na quarta etapa, no momento em que for estabelecida a quantidade de opções de preços para escolha dos pesquisados. Deve-se instruir que não há limites para o preço e, se o cliente estiver disposto a pagar um preço diferente do que está listado, ele poderá citá-lo, que será registrado no questionário. As etapas de identificação e elaboração de cálculos podem ser trabalhosas, porém devem ser realizadas buscando informações fidedignas.

O modelo proposto pode ser considerado de fácil aplicação, porém moroso, devido à necessidade de, além de realizar a pesquisa com os consumidores, realizar levantamento de custos e elaboração de cálculos de análise de investimentos. Os entrevistados podem demorar a decidir o local da classificação.

Como ponto forte encontrado, está a construção de uma ferramenta de suporte à decisão daqueles que estão dispostos a investir nas organizações para alcançar uma gestão ambiental adequada. Outro ponto forte é a possibilidade de identificação do perfil dos clientes da empresa que valorizam a questão ambiental para aquisição de produtos.

Espera-se que a proposta apresentada neste artigo, seja utilizada pelos gestores das organizações como uma ferramenta gerencial que possa identificar, com base no valor para os clientes, a maneira adequada de agir, ligando os aspectos ambientais e competitivos.

\section{Referências}

ABREU, M. C. S. Modelo de avaliação da estratégia ambiental: uma ferramenta para tomada de decisão. 2001. 232 f. Tese (Doutorado em Engenharia de Produção e Sistemas)-Universidade Federal de Santa Catarina, Florianópolis, 2001.

ALBERTON, A. Meio ambiente e desempenho econômico financeiro: o impacto da isso 14001 nas empresas brasileiras. 2003. Tese (Doutorado em Engenharia de Produção)-Universidade Federal de Santa Catarina, Florianópolis, 2003.

ANDRADE, R. O. B.; TACHIZAWA, T.; CARVALHO, A. B. Gestão Ambiental: Enfoque estratégico aplicado ao desenvolvimento sustentável. 2. ed. São Paulo: Makron Books, 2002.

AZEVEDO, M. S.; LIMA FILHO, R. O.; LUCENA, W. G. L. Gestão ambiental: um estudo de caso aplicado à hidroponia. In: ASSEMBLÉIA DO CONSELHO LATINO-AMERICANO DE ESCOLAS DE ADMINISTRAÇÃO, 2002, Porto Alegre. Anais... Porto Alegre, 2002.

BARBOSA FILHO, J. Modelo de valoração ambiental para análise de propostas de investimento. 2005. 135 f. Tese (Doutorado em Engenharia de Produção e Sistemas)-Universidade Federal de Santa Catarina, Florianópolis, 2005.

BERTOLINI, G. R. F.; POSSAMAI, O. Proposta de Instrumento de Mensuração do Grau de Consciência Ambiental, do Consumo Ecológico e dos Critérios de Compra dos Consumidores. Revista de Ciência e Tecnologia, v. 13, p. 19-27, 2005.

BOCKERMANN, A. et al. Modelling Sustainability. Comparing an Econometric (PANTA RHEI) and a Systems Dynamics Model (SuE). Journal of Policy Modeling, v. 27, p. 189-210, 2005. http://dx.doi. org/10.1016/j.jpolmod.2004.11.002 
BORBA, P. R. T. Relação entre desempenho social corporativo e desempenho financeiro de empresas no Brasil. In: ENCONTRO NACIONAL DA ASSOCIAÇÃO NACIONAL DOS PROGRAMAS DE PÓS-GRADUAÇÃO EM ADMINISTRAÇÃO, 30., 2006, Salvador. Anais... Salvador: ANPAD, 2006.

BRANDALISE, L. T. et al. A percepção e o comportamento ambiental dos universitários em relação ao grau de educação ambiental. Revista Gestão \& Produção, v. 16, n. 2., p. 286-300, 2009.

BRASIL. Ministério do Desenvolvimento, Indústria e Comércio Exterior. Consumidor desiste de comprar produto com selo verde se ele for mais caro. Disponível em: <http://www.portaldoconsumidor.gov. br/homologacao/ noticia.asp?busca=sim\&id=12026>. Acesso em: 11 nov. 2008.

CESAR, J. F.; SILVA JUNIOR, A. A relação entre a responsabilidade social e ambiental com o desempenho financeiro: um estudo empírico na Bovespa no período de 1999 a 2006. In: ENCONTRO DA ASSOCIAÇÃO NACIONAL DOS PROGRAMAS DE PÓS-GRADUAÇÃO EM CIÊNCIAS CONTÁBEIS, 2., 2008, Salvador. Anais... Salvador: ANPCONT, 2008.

CHURCHILL, G. A.; PETER, J. P. Marketing: criando valor para o cliente. 2. ed. São Paulo: Saraiva, 2000.

DONAIRE, D. A internalização da gestão ambiental na empresa. Revista Brasileira de Administração, v. 31, n. 1, p.44-51, jan./mar. 2001.

D'SOUZA, C. Ecolabels programmes: a stakeholder (consumer) perspective. Corportare Communication: An International Journal, v. 9, n. 3, p. 179-188, 2004.

DURÁN, O.; PUGLIA, V. B. Scorecard ambiental: monitoração dos custos ambientais através da web. Revista chilena de ingeniería, v. 15, n. 3, p. 291-301, 2007.

EPELBAUM, M. A influência da gestão ambiental na competitividade e no sucesso empresarial. 2004. $190 \mathrm{f}$. Dissertação (Mestrado em Engenharia de Produção)-Escola Politécnica da Universidade de São Paulo, São Paulo, 2004.

FA, M. C. et al. Using environmental management systems to increase firms' competitiveness. Corporate Social Responsibility and Environmental Management, v. 10, p. 101-110, 2003.

FREIMANN, J.; WALTHER, M. The impacts of corporate environmental management systems: a comparison of EMAS and ISO 14001. Greener Management International, v. 36, p. 91-104, 2001.

GAVRONSKI, I.; FERRER, G.; PAIVA, E. L. ISO 14001 Certification in Brazil: motivations and benefits. Journal of Cleaner Production, v. 16, n. 1, p. 87-94, 2008. http://dx.doi.org/10.1016/j.jclepro.2006.11.002

HUNT, C. B.; AUSTER, E. R. Proactive environmental management: avoiding the toxic trap. Sloan Management Review, v. 31, n. 2, p. 7-18, 1990.

MAIA, G. L.; VIEIRA, F. G. D. Marketing Verde: estratégias para produtos ecologicamente corretos. Revista de Administração Nobel, v. 03, p. 21-32, 2004.

MEDEIROS, D. D.; SILVA, G. C. S. Análise do gerenciamento ambiental em empresas do estado de pernambuco. In: ENCONTRO NACIONAL DE ENGENHARIA DE
PRODUÇÃO, 23., 2003, Ouro Preto. Anais... Ouro Preto, 2003.

NAGLE, T. T.; HOLDEN, R.K. Estratégias e táticas de preços: um guia para decisões lucrativas. São Paulo: Pearson Prentice Hall, 2003.

OMETTO, A. R.; SOUZA, M. P.; GUELERE FILHO, A. A gestão ambiental nos sistemas produtivos. Revista Pesquisa e Desenvolvimento Engenharia de Produção, v. 6, p. 22-36, 2007.

ORELLANO, V. I. F.; QUIOTA, S. Análise do retorno dos investimentos socioambientais das empresas brasileiras. Revista de Administração de Empresas, v. 51, n. 5, 2011.

PASSOS, L. A. N. Gestão ambiental e competitividade: um estudo do setor químico brasileiro. 2003. 166 f. Dissertação (Mestrado em Gestão de Negócios)Universidade Estadual de Maringá, Maringá, 2003.

REINARTZ, W. J.; KUMAR, V. The impact of customer relationship characteristics on profitable lifetime duration. Journal of Marketing, v. 67, n. 1, p. 77-99, 2003. http:// dx.doi.org/10.1509/jmkg.67.1.77.18589

ROHRICH, S. S.; CUNHA, J. C. A proposição de uma taxonomia para a análise da gestão ambiental no Brasil. Revista de Administração Contemporânea, v. 8, n. 4, p. 86-95, 2004.

SCHULTZ, P. W. et al. Implicit connections with nature. Journal of Environmental Psychology, v. 24, p. 31-42, 2004. http://dx.doi.org/10.1016/ S0272-4944(03)00022-7

SEIFFERT, M. E. B. ISO 14001: Sistemas de gestão ambiental. São Paulo: Atlas, 2005.

SILVA, A. A. Gestão ambiental e competitividade: o caso BRASILAMARRAS. 2001. 275 f. Dissertação (Mestrado em Ciência Ambiental)-Universidade Federal Fluminense, Niterói, 2001.

VELUDO-DE-OLIVEIRA, T. M.; IKEDA, A. A. O conceito de valor para o cliente: definições e implicações gerenciais em marketing. Revista Eletrônica de Gestão Organizacional, v. 3, n. 1, 2005.

VOLSKY, R. P.; OZANNE, L. K.; FONTENOT, R. J. A conceptual model of US consumer willingness-to-pay for environmentally certified wood products. Journal of Consumer Marketing, v. 16, n. 2, p. 122-140, 1999. http://dx.doi.org/10.1108/07363769910260498

WALKER, D.; PITT, M.; THAKUR, U. J. Environmental management systems: Information management and corporate responsibility. Journal of Facilities Management, v. 5, n. 1, p. 49-61, 2007. http://dx.doi. org/10.1108/14725960710726346

WATSON, M.; EMERY, R. T. A. Environmental management and auditing systems: the reality of environmental self-regulation. Managerial Auditing Journal, v. 19, n. 7, p. 916-928, 2004. http://dx.doi. org/10.1108/02686900410549439

ZUTSHI, A.; SOHAL, A. A study of the environmental management system (EMS) adoption process within Australasian organizations. Technovation, v. 24, n. 5, p. 371-386, 2004. http://dx.doi.org/10.1016/ S0166-4972(02)00115-3

WALDMAN, M.; SCHNEIDER, D. M. Guia ecológico doméstico. São Paulo: Contexto, 2000 